consider it unlikely that a larger dose of this surfactant would have produced more dramatic changes, as $25 \mathrm{mg}$ is far in excess of that required for a monolayer throughout the lung. The initial Crs values in the surfactant treated babies were marginally higher than those in the control group, reflecting perhaps the fact that the group as a whole was relatively more mature. Both groups showed a trend towards improved compliance after the instillation, probably representing improved aeration and clearance of alveolar fluid.

We conclude that giving artificial surfactant at birth does not have any immediate, dramatic effect on lung mechanics of preterm babies. The two treatment groups had similar subsequent courses, but it is not possible to state in this small series whether surfactant has a prophylactic value in IRDS in some infants.

We thank Dr Colin Morley, New Addenbrooke's Hospital Cambridge, who prcvided us with the surfactant powder. This work was funded by a grant from the Medical Research Council.

\section{References}

${ }^{1}$ Fujiwara T, Maeta H, Chida S, Morita T, Watabe Y, Abe T. Artificial surfactant therapy in hyaline membrane disease. Lancet 1980;i:55-9.

${ }^{2}$ Hallman M, Merritt TA, Schneider H, et al. Isolation of human surfactant from amniotic fluid and a pilot study of its efficacy in respiratory distress syndrome. Pediatrics 1983;71:473-82.

${ }^{3}$ Milner AD, Vyas H, Hopkin IE. Effects of artificial surfactant on lung function and blood gases in idiopathic respiratory distress syndrome. Arch Dis Child 1983;58:458-60.

${ }^{4}$ Morley CJ, Bangham AD, Miller N. Davis JH. Dry artificial lung surfactant and its effect on very premature babies. Lancet $1981 ; \mathbf{i}: 64-8$

5 Wilkinson AR, Jeffrey JA, Jenkins PA. Controlled trials of dry surfactant in preterm infants (abstract). Arch Dis Child 1982;57:802.

${ }^{6}$ Vyas H, Milner AD, Hopkin IE. Physiological responses to prolonged and slow rise inflation. $J$ Pediatr 1981;98:635-40.

Correspondence to Professor A D Milner, Department of Neonatal Medicine and Surgery, City Hospital, Hucknell Road, Nottingham NG5 1PB.

Received 21 October 1983

\title{
Febrile convulsions: electroencephalographic changes related to rectal temperature
}

\author{
P E MINCHOM AND S J WALLACE \\ University Hospital of Wales, Heath Park, Cardiff
}

SUMMARY Nine children had simultaneous continuous electroencephalographic monitoring and temperature recording immediately after febrile convulsions. Background electroencephalographic rhythms did not alter with temperature and with one exception, seizure discharges occurred only during sustained high pyrexia.

The relation between electroencephalographic and electrocardiographic changes and body temperature over periods up to 25 hours starting as soon as possible after febrile convulsions is examined. The findings are related to short term outlook.

\section{Patients and methods}

Nine children admitted to hospitals in Cardiff after febrile convulsions during 1982 were studied. All had had generalised fits that lasted less than 10 minutes and none had received diazepam.

The patients were examined clinically between 1.5 and 5 hours (mean 3.3 hours) after the convulsion. Rectal temperatures were recorded hourly using a mercury in glass thermometer. A Medilog (Oxford Instruments) four channel recorder with two electroencephalographic, one electrocardiographic, and one timing channel was used for recordings, which started from 2.75 hours to 10.5 hours (mean 4.7 hours) after the febrile convulsion and continued for 11 to 25 hours (mean $15 \cdot 8$ hours). The electroencephalographic montage used was F3-P3, F4-P4 in the 10-20 system.

The electroencephalographs were subsequently examined on the Medilog monitor display unit without reference to temperature recordings. A flow chart was composed for each child consisting of the speeds of the basic rhythms in a typical section of the tape for each hour, coinciding with the temperature recordings. Each tape was scrutinised for paroxysmal activity and a note was made of any asymmetry. Once the electroencephalograph had been analysed the temperature measurements were 
added to the chart. All the children were examined again between three and 10 months (mean $4 \cdot 6$ months) later.

\section{Results}

No child had a frank convulsion during the recording. In 8 patients the temperature on hospital admission was between $38^{\circ}$ and $39 \cdot 5^{\circ} \mathrm{C}$ and one child was apyrexial. In all children temperature was raised during recording -6 had a low grade fever (maximum $38^{\circ} \mathrm{C}$, pyrexial for less than $30 \%$ of recording) and the remainder had a high grade fever (maximum $39.5^{\circ}$ to $40^{\circ} \mathrm{C}$, pyrexial for more than $40 \%$ of recording).

The features of the recordings are summarised in the Table. No consistent pattern emerged to suggest a relation between the frequencies of the background activity and the grade of fever (Figure). Assessment of trends on individual charts did not produce further evidence for a relation between the degree or progress of the pyrexia and the basic rhythms. In no case did asymmetry show any relation to temperature. Six children had runs of high voltage slow activity, three while pyrexial and three while apyrexial.

Epileptic activity was seen in the electroencephalographs of four children. Intermittent spikes occurred in all three children with high grade fever once the pyrexia was sustained, but they did not show as the temperature was rising. In two of the three, the spikes persisted for one and three hours after the temperature settled. One child, whose parents both had histories of seizures, sustained only a low grade fever but spikes and spike and wave activity were seen when she was apyrexial. A further two children had bursts of spike and wave activity during high grade fever.
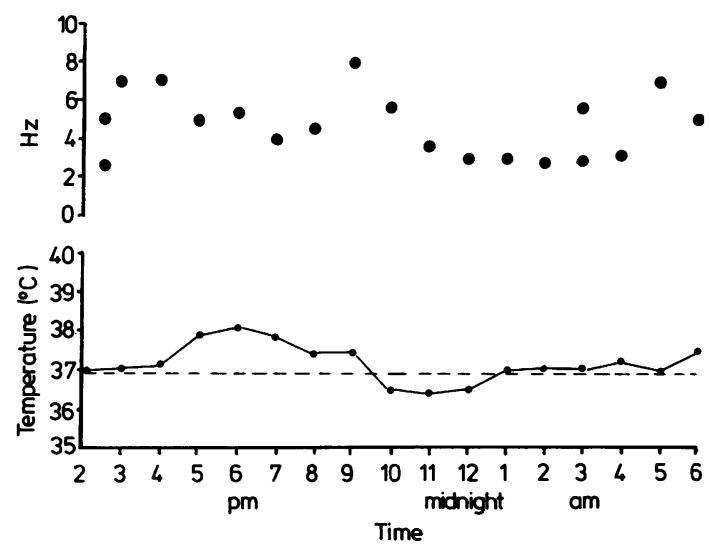

Figure Background electroencephalographic rhythm and temperature chart from 4.5 hours after a febrile convulsion.

Sharp activity was observed in two patients while apyrexial, in recordings which were otherwise free from abnormalities. In the three children with high grade fever sharp activity was observed during rising temperature, sustained fever, and falling temperature.

The electrocardiographs showed occasional sinus or nodal ectopic beats, but no dysrhythmias. In particular, no episodes of asystole were observed at any time.

During follow up, although four of the 9 children had further febrile illnesses, only one had a subsequent febrile convulsion. She had had a low grade fever during the first illness, with no epileptic activity shown on the electroencephalograph. All children were considered neurologically within normal limits when examined at follow up.

Table Grade of fever and features of electroencephalographic (EEG) recordings in 9 children after febrile convulsions

\begin{tabular}{|c|c|c|c|c|c|c|}
\hline \multirow{2}{*}{$\begin{array}{l}\text { Case } \\
\text { No }\end{array}$} & \multirow{2}{*}{$\begin{array}{l}\text { Grade of } \\
\text { fever }\end{array}$} & \multirow[t]{2}{*}{ Symmetry } & \multicolumn{4}{|l|}{$E E G$ findings } \\
\hline & & & $\begin{array}{l}\text { High voltage } \\
\text { slow }\end{array}$ & Spikes & $\begin{array}{l}\text { Spike and } \\
\text { wave }\end{array}$ & $\begin{array}{l}\text { Sharp } \\
\text { activity }\end{array}$ \\
\hline 1 & L & $\mathrm{S}$ & + & - & - & - \\
\hline 2 & L & $\mathrm{S}$ & + & + & + & - \\
\hline 3 & $\mathrm{~L}$ & A/S $\mathrm{S}^{*}$ & + & - & - & - \\
\hline 4 & $\mathrm{~L}$ & + & - & - & - & + \\
\hline 5 & $\mathrm{H}$ & $\mathrm{A} / \mathrm{S}$ & + & + & + & + \\
\hline 6 & $\mathrm{~L}$ & S & - & - & - & - \\
\hline 7 & $\mathrm{~L}$ & $\mathrm{~S}$ & + & - & - & + \\
\hline 8 & $\mathbf{H}$ & S & - & + & + & + \\
\hline 9 & $\mathbf{H}$ & S & + & + & - & + \\
\hline
\end{tabular}

$\mathrm{L}=$ low grade (temperature $\leqslant 38^{\circ} \mathrm{C}$, pyrexial $<30 \%$ of recording).

$\mathrm{H}=$ high grade (temperature $\geqslant 38^{\circ} \mathrm{C}$, pyrexial $>40 \%$ of recording).

$\mathrm{S}=$ symmetrical.

A/S = asymmetrical.

Initially asymmetrical becoming symmetrical after five hours.

"Poor contact on one electrode. 


\section{Discussion}

Although several predisposing factors have been identified $^{1-3}$ the trigger for febrile convulsion remains elusive. Previous studies have shown slowing of background rhythms during and after pyrexial illnesse ${ }^{3}$ and during artificially induced fever. ${ }^{4}$ The background rhythms in the present study were generally slower than expected for the children's ages but no fluctuation with temperature was detected, suggesting the slowing is caused by an effect of the infection other than fever.

It has been suggested that fever precipitates reflex anoxic seizures that progress to typical febrile convulsions. ${ }^{6}$ None of the present children had asystole, and seizure activity occurred independently of cardiac rhythm. We are unable to exclude asystole as the final precipitating event for clinically observable seizures, but seizure activity in this study could not be attributed to anoxia. Our findings did not help to predict early recurrences of febrile convulsion.
We thank Miss J Gibbs for technical assistance and Miss M Chilcott for secretarial assistance.

\section{References}

${ }^{1}$ Lewis HM, Parry JV, Parry RP, et al. Role of viruses in febrile convulsions. Arch Dis Child 1979;54:869-76.

${ }^{2}$ Wallace SJ. Pyrexial convulsions. In: Rose FC, ed. Paediatric neurology. Oxford: Blackwell, 1979:346-59.

${ }^{3}$ Wallace SJ, Zealley H. Neurological, electroencephalographic and virological findings in febrile children. Arch Dis Child 1970;45:611-23.

${ }^{4}$ Baird HW, Garfunkel JM. EEG changes in children with artificially induced hyperthermia. J Pediatr 1956;48:28-33.

${ }^{5}$ Millichap JG. Studies in febrile seizures. I. Height of body temperature as a measure of the febrile seizure threshold. Pediatrics 1959;23:76-85.

${ }^{6}$ Stephenson JBP. Two types of febrile seizure, anoxic (syncopal) and epileptic mechanisms differentiated by oculocardiac reflex. Br Med J 1978;ii:726-8.

Correspondence to Dr S J Wallace, University Hospital of Wales, Heath Park, Cardiff CF4 4XW.

Received 11 December 1983

\title{
Weight as the best standard for glomerular filtration in the newborn
}

\author{
M G COULTHARD AND E N HEY \\ Department of Child Health, University of Newcastle upon Tyne
}

SUMMARY The relation between surface area and body weight changes dramatically in infancy. In 31 healthy infants of 27 to 40 weeks' gestation, variations in glomerular filtration rate were reduced more than twofold by choosing glomerular filtration rate/kg body weight rather than glomerular filtration rate $/ \mathrm{m}^{2}$. The former provides the most useful and practical index of renal function in the neonate.

Although the use of surface area for standardising glomerular filtration rate minimises age and weight dependent variations in children and adults, this has never been tested in infancy, when surface area:weight changes most dramatically. We have, therefore, tested glomerular filtration rate data from preterm and term babies to find which standard reduces the variation most effectively.

\section{Patients and methods}

Thirty one well babies of 27 to 40 weeks' gestation weighing 0.68 to $3.7 \mathrm{~kg}$ were studied between 2 and 7 days of age. Twenty five $(81 \%)$ of the infants were below the 50th centile for weight and $11(35 \%)$ were below the 10th. Glomerular filtration rate was measured by the 24 hour constant inulin infusion method $^{1}$ on average three times for each baby, and the mean value taken. Surface area was estimated by Boyd's formula ${ }^{2}$ and a weight index was calculated as weight:50th centile weight. The study had the approval of the local ethical committee, and informed parental consent was obtained.

\section{Results}

Glomerular filtration rate values varied more than 10 fold between babies $(0.50$ to $5.71 \mathrm{ml} / \mathrm{min})$, but only fivefold when expressed per unit surface area $\left(4.5\right.$ to $\left.22.6 \mathrm{ml} / \mathrm{min} / \mathrm{m}^{2}\right)$ and less than threefold when expressed per unit body weight $(0.59$ to 1.56 $\mathrm{ml} / \mathrm{min} / \mathrm{kg}$ ). Glomerular filtration rate $/ \mathrm{m}^{2}$ and glomerular filtration rate $/ \mathrm{kg}$ were each positively correlated with weight $(\mathrm{P}<0.001)$, gestational age $(\mathrm{P}<0 \cdot 001)$, and weight index $(\mathrm{P}<0 \cdot 05)$. Multiple 